
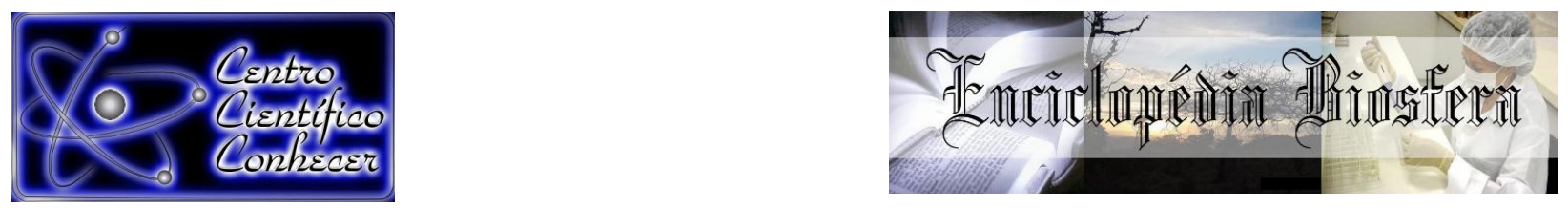

\title{
AVALIAÇÃO DOS IMPACTOS AMBIENTAIS, SOCIAIS E ECONÔMICOS DECORRENTES DO DESENVOLVIMENTO URBANO NO MUNICÍPIO DE MARICÁ
}

\footnotetext{
Hellen Rigo Fabricio ${ }^{1}$, Dirlane de Fátima do Carmo², Cristina Moll Hüther ${ }^{3}$, Daniel Henrique Nogueira Dias ${ }^{4}$, Daiane Cecchin ${ }^{5}$

${ }^{1}$ Mestranda em Engenharia, Pelo Programa de Pós-Graduação em Engenharia de Biossistemas da Universidade Federal Fluminense, Niterói, Brasil (hellen.rigo@gmail.com)

${ }^{2}$ Docente no Departamento de Engenharia Agrícola e do Meio Ambiente da Universidade Federal Fluminense, Niterói, Brasil

${ }^{3}$ Pós-Doutoranda do Programa de Pós-Graduação em Engenharia de Biossistemas da Universidade Federal Fluminense, Niterói, Brasil

${ }^{4}$ Docente no Departamento de Engenharia Elétrica da Universidade Federal Fluminense, Niterói, Brasil

${ }^{5}$ Docente no Departamento de Engenharia Agrícola e do Meio Ambiente da Universidade Federal Fluminense, Niterói, Brasil

Recebido em: 06/04/2018 - Aprovado em: 10/06/2018 - Publicado em: 20/06/2018 DOI: 10.18677/EnciBio_2018A17
}

Os indicadores podem utilizados como ferramenta supervisória da eficiência da administração pública em amparar áreas vitais, mensurando os impactos no ambiente e na sociedade decorrentes do acelerado desenvolvimento urbano. $O$ presente trabalho teve como objetivo analisar os impactos ambientais, sociais e econômicos, decorrentes do desenvolvimento urbano por meio de indicadores de sustentabilidade para o município de Maricá - RJ dentro do estado do Rio de Janeiro, com base nas variáveis locais propostas (características socioeconômicas e ambientais). Foram utilizados dados estatísticos qualitativos (coletados de bases nacionais, fundações e organizações não governamentais) e realizadas análises comparativas com outras regiões do estado, considerando o melhor e o pior cenário. Os índices de sustentabilidade ambiental, social, econômico e geral encontrados para o município de Maricá, de acordo com as variáveis propostas foram respectivamente 0,$4173 ; 0,4431 ; 0,2537$ e 0,3893, o que demonstra a necessidade de aprimoramento nas dimensões da sustentabilidade avaliada neste estudo. Para tanto medidas que mitiguem os impactos de causa-efeito, como melhorias na infraestrutura, saúde, renda, conservação de áreas de preservação permanente são imprescindíveis.

PALAVRAS-CHAVE: indicadores, sustentabilidade, sustentável.

\section{EVALUATION OF THE ENVIRONMENTAL, SOCIAL AND ECONOMIC IMPACTS OF UBRBAN DEVELOPMENT IN THE MUNICIPALITY OF MARICÁ}

\section{ABSTRACT}


Indicators can be used as a supervisory tool for the efficiency of public administration in supporting vital areas, measuring the impacts on the environment and society resulting from accelerated urban development. The objective of this study was to analyze the environmental, social and economic impacts of urban development through sustainability indicators for the municipality of Maricá - RJ, in the state of Rio de Janeiro, based on the proposed local variables (socioeconomic characteristics and environmental). Qualitative statistical data (collected from national databases, foundations and non-governmental organizations) were used and comparative analyzes were carried out with other regions of the state, considering the best and worst case scenarios. The environmental, social, economic and general sustainability indexes found for the municipality of Maricá, according to the proposed variables were respectively $0.4173 ; 0.4431 ; 0.2537$ and 0.3893 , which demonstrates the need for improvement in the dimensions of sustainability evaluated in this study. For both measures to mitigate cause-effect impacts, such as improvements in infrastructure, health, income, and conservation of permanent preservation areas are essential.

KEYWORDS: indicators, sustainability, sustainable.

\section{INTRODUÇÃO}

O desenvolvimento econômico e social permanente está intrinsecamente ligado às boas práticas ambientais, visto que da natureza extrai-se os recursos necessários para manutenção da vida, além de boa parte dos recursos que manipulados transformam-se em energia, combustível para o progresso. Assim, como observado por Sanches e Schmidt (2016) a vertente do crescimento sustentável possui intima dependência com a conservação dos recursos naturais, portanto esses aspectos necessitam estar em equilíbrio. Neste cenário desenvolvimentista, a sociedade desempenha um papel no planejamento contínuo da ocupação, e estabelece subsídios e ações pró ambientais que culminam em frutos sustentáveis no processo de desenvolvimento (DE OLIVEIRA; LIMA, 2003).

Dentro desta lógica e tomando cada região como única, a mensuração de variáveis locais para a criação de indicadores de sustentabilidade customizados, torna-se basilar para a criação de políticas públicas nos âmbitos social, econômico e ambiental que fomentem o desenvolvimento de modo sustentável. A carência desses indicadores culmina em políticas sem paridade que não favorecem a fluidez das atividades produtivas e o diálogo entre os temas relevantes às necessidades da sociedade local (SILVA et al., 2017).

Com a crescente inquietação a despeito do desenvolvimento harmônico das sociedades com o meio, os indivíduos passaram a sistematizar mecanismos de controle e supervisão das atividades antrópicas. O conhecimento das condições ambientais, sociais e econômicas, tornou-se então o recurso mais valioso na tomada de decisões públicas (MORAIS et al., 2014). Para auxiliar nessas decisões os indicadores constituem uma ferramenta importante que permite a condução do desenvolvimento de modo sustentável (BORGES et al., 2018).

Assume-se como fundamental observação que a avaliação por indicadores de sustentabilidade efetua-se de modo correto somente quando considerada concomitantemente a tríade dimensional estruturada pelas esferas ambiental, econômica e social. Medidas que abarquem as três competências refletem diretamente na qualidade de vida e bem estar populacional (VEIGA, 2010).

O zoneamento ecológico-econômico, adicionalmente se configura um instrumento imprescindível na interação com os sistemas ecológicos, mitigando os 
impactos ambientais negativos e conferindo à população segurança na continuidade da manutenção dos recursos naturais (RUFFATO-FERREIRA et al., 2018). Alterações severas no meio podem conduzir o equilíbrio natural ao seu limite, ameaçando a resiliência do mesmo, sendo capaz de culminar em perda de vidas. Assim, as atividades antrópicas carecem de um intenso monitoramento para assegurar que os limites de sustentabilidade do meio não sejam ultrapassados (KOTSUBO et al., 2017).

Os indicadores de sustentabilidade como ferramentas de gerenciamento no desenvolvimento sustentável fornecem informações em diversos horizontes como, ambiental, socioeconômico, cultural, econômico, institucional entre outros. A utilização desses indicadores tem por objetivo quantificar as informações reunidas, de modo a facilitar a compreensão de variáveis complexas tornando a comunicação mais fluida e ação mais efetiva na correção e mitigação dos impactos, como apontaram Vieira e Bruxel (2015) em seu trabalho. A compreensão desses fenômenos permite a verificação das ações humanas e o estudo da sua influência no ecossistema.

Neste âmbito, a proposição, levantamento e análise de indicadores de sustentabilidade são importantes como dispositivo de reconhecimento da condição atual do local e do nível de interferência neste cenário. Contudo esta análise de indicadores deve ser baseada em dados históricos já conhecidos e envolver o maior número na relação entre os índices possíveis. Desta forma os indicadores estarão mais próximos de narrar um panorama real. $O$ presente trabalho teve como objetivo analisar os impactos ambientais, econômicos e sociais através da reunião de indicadores de sustentabilidade propostos para o município de Maricá - RJ com base nas variáveis locais, características socioeconômicas e ambientais.

\section{MATERIAL E MÉTODOS}

\section{Classificação e Uso dos Indicadores}

A Organização para Cooperação e Desenvolvimento Econômico (OCDE) criou o método de Pressão- Estado- Resposta (PER), baseado no conceito de causalidade. Este método expõe que a pressão das atividades desenvolvidas pelo homem no meio ambiente, relaciona-se a mudança de estado do mesmo, visto que altera a qualidade e quantidade de recursos naturais disponíveis. Assim, a sociedade responde a essas mudanças através de políticas econômicas, ambientais ou setoriais. Este método corrobora a conexão entre atividade humana e meio ambiente, ajudando a sociedade a perceber as interações antrópicas na natureza e tomar decisões que perpetuem esse bom convívio (OCDE,1993). Para esta proposta foram escolhidos indicadores de sustentabilidade que se relacionam ao método PER.

O eixo temático que a proposta aborda situa-se na trinca de perspectivas, ambiental, econômica e social, que governam os fundamentos do desenvolvimento sustentável. Adotados como pressupostos de importância elementar na avaliação de desempenho de cidades. Estes parâmetros quando observados conjuntamente na óptica ambiental, econômica e social são tidos como completos nas características dimensionais. A seguir, a definição das perspectivas abordadas: 
- Ambiental: esta dimensão se refere aos impactos no meio ambiente, abarca indicadores de qualidade no que tange o solo, ar e água;

- Econômica: esta dimensão se refere aos impactos sobre as condições econômicas da população, os indicadores relacionam o nível de emprego, consumo e renda;

- Social: esta dimensão da sustentabilidade se refere aos impactos nos sistemas sociais, identificando os aspectos relacionados à educação, saúde e habitação.

A determinação das variáveis para compor os indicadores de sustentabilidade substanciais para caracterização do município de Maricá diligenciou filtrar os parâmetros de modo a alcançar índices que possam refletir a realidade local dentro do cenário atual. A obtenção de dados amiúde apresentou-se como um entrave na outorga de sensibilidade para a informação ambicionada, problema também aludido por Braga (2004) em seu trabalho. De tal modo, a seguir encontram-se as variáveis propostas para a avaliação, guarnecidas pelas descrições respectivas.

\section{Variáveis Propostas para Formação dos Indicadores}

\section{Dimensão Social}

A dimensão social com indicadores nos eixos de saúde, educação e habitação abriga a complexidade da aplicação de métricas, e o óbice dos resultados das ações nessa dimensão serem notados apenas no longo prazo (FIORE et al., 2007). O intento na formação deste índice é avaliar o estado geral dos habitantes do município de Maricá, uma vez que o estado de saúde da população, o seu nível de educação e a qualidade das moradias instituem um importante qualificador de bemestar social. Altamente atrelada às dimensões econômica e ambiental, a dimensão social torna-se uma das menos exploradas nos estudos. Acarretando na descaracterização da população como agente responsável por determinar o nível de bem estar econômico e ambiental.

O eixo da saúde abrange questões de morbidade dos indivíduos, número de leitos hospitalares e unidades de a saúde disponíveis para a população. As variáveis relacionadas com a saúde escolhidas para essa dimensão buscaram aferir as condições de prevenção e de tratamento oferecidas pelo município de Maricá. A escolha das variáveis deste eixo pautou-se nos critérios de relevância para o setor da saúde estabelecidos no controle de gestão do Sistema Único de Saúde (REDE INTERAGENCIAL DE INFORMAÇÃO PARA A SAÚDE, 2008). A prevenção pode ser ponderada pelas variáveis de mortalidade e natalidade, pois essas sinalizam ações passadas referentes ao tratamento da população. Para aferir as condições de tratamento, empregou-se a disponibilidade dos estabelecimentos de saúde, disponíveis no município, avaliada na proporção de dez mil habitantes, estudando as condições de oferta com a densidade populacional.

O eixo da educação engloba as taxas de alfabetização e escolaridade da população. As variáveis nesse eixo buscam alinhar como a educação pode ser um fator na capacidade produtiva e de que forma isto pode trazer mais riqueza traduzida em renda, de modo a aumentar a qualidade de vida da população municipal. O eixo da habitação trata das condições de moradia. Apura as condições de habitação da população e se a mesma possui acesso apropriado ao sistema de saneamento básico. A habitação consiste em um direito social e está intimamente ligada ao bem estar populacional. 
Na busca por dados na dimensão social, foi utilizado como base referencial o Cadastro Nacional de Estabelecimentos de Saúde (CNES)(DATASUS, 2018), e o banco de dados do estado do Rio de Janeiro do Instituto Brasileiro de Geografia e Estatística (IBGE) (IBGE, 2018).

\section{Dimensão Econômica}

A dimensão econômica conta com variáveis nos eixos do nível de empregabilidade, que se refletem na renda, e, por conseguinte, no consumo. Dialogando intimamente com o desenvolvimento e com a geração de uma melhor qualidade de vida para a população, por caminhos que designem o menor impacto ambiental possível. Abalizada como um pilar de ponderação, o índice formado nesta dimensão, tem por objetivo detectar a vulnerabilidade da população na pretensão de níveis de renda mais elevados e inferir a estabilidade oferecida pela renda gerada.

O eixo da empregabilidade conta com a taxa média de emprego da população maior de dezoito anos e com o percentual de pessoas vulneráveis à pobreza no município. Complementarmente, o nível de renda da população é apurado para a formação do índice. Na busca de dados na dimensão social, foi utilizado como base referencial o banco de dados do estado do Rio de Janeiro do Instituto Brasileiro de Geografia e Estatística (IBGE, 2018).

\section{Dimensão Ambiental}

A dimensão ambiental com variáveis nos eixos de água, ar e solo comporta o enredamento de questões inerentes ao crescimento econômico e populacional e suas pressões. A degradação dos sistemas ambientais não ameaça unicamente as próximas gerações, mas coloca em perigo a população atual. Os efeitos nocivos dessa degradação impactam a qualidade de vida da população do município de forma generalizada (BRITO et al., 2013).

O eixo do ar é concebido pela união de taxas de concentração de material particulado, monóxido de carbono, dióxido de nitrogênio, dióxido de enxofre e concentrações de enxofre. Todas essas taxas reunidas instituem a variável de qualidade do ar (SILVA et al., 2017), que está intimamente relacionado à qualidade de vida no município. Um bom índice neste eixo corrobora uma saúde melhor para a população e também menor gasto da administração pública (BRASIL, 2009).

O eixo do solo profundamente atado ao padrão de urbanização municipal consideram variáveis de área verde, área desmatada e quantidade de resíduos per capta. O infortúnio neste eixo figura-se na impossibilidade de formação de uma sustentabilidade urbana singular. A problemática ambiental neste quesito deve ser capaz de agregar elementos capazes de unificar todas as ações urbanísticas. Configurando assim um desafio à administração municipal.

O eixo da água é de fundamental importância para a sobrevivência humana. A utilização abusiva e o avanço nos eixos econômico e social provocam pressões que culminam em poluição e colocam em pauta a qualidade dos recursos hídricos, cada vez mais ameaçados. Na composição deste eixo encontram-se as variáveis de perda de água potável, o nível de abastecimento público em área urbana e a qualidade da água ofertada à população.

$\mathrm{Na}$ busca por dados na dimensão ambiental, foi utilizado como base referencial os bancos de dados do Instituto Brasileiro de Geografia e Estatística (IBGE, 2017), o plano municipal de saneamento básico de Maricá (PMSB, 2017), o diário oficial do estado do Rio de Janeiro (DOERJ, 2017), o Instituto Brasileiro de 
Análises Sociais e Econômicas (INCID, 2016) e estudos do Instituto Trata Brasil (OLIVEIRA et al., 2015).

\section{Cálculo dos Índices}

Considerando a necessidade de abordar a sustentabilidade de forma abrangente, a dificuldade de obtenção de dados levou os autores à utilização de poucas variáveis por dimensões na composição de um Índice de Sustentabilidade Municipal. As variáveis escolhidas, já citadas e explicitadas no Quadro 1, foram representadas com base em diversas estatísticas e pesquisas realizadas por órgãos dos governos municipal, estadual e federal, por meio de suas secretarias, fundações, organizações e instituições, uma vez que os autores não realizaram pesquisa de campo para o levantamento de dados primários.

QUADRO 1. Escolha das variáveis por dimensão.

\begin{tabular}{|c|c|}
\hline Dimensões & Variável \\
\hline \multirow{8}{*}{ Ambiental } & $\begin{array}{c}\text { Abastecimento Água potável } \\
\text { área urbana (domicílios) }\end{array}$ \\
\hline & $\begin{array}{c}\text { Perda de água tratada (média anual } \\
\text { diária) }\end{array}$ \\
\hline & Qualidade de água \\
\hline & $\begin{array}{c}\text { Média Per capita de resíduos }(\mathrm{kg} / \\
\text { dia.hab) }\end{array}$ \\
\hline & Índice de área verde $\mathrm{m}^{2}$ \\
\hline & ICMS verde (IFCA) \\
\hline & Área Desmatada $\left(\mathrm{km}^{2}\right)$ \\
\hline & Indicadores Qualidade AR \\
\hline \multirow{6}{*}{ Social } & Unidades Saúde / 10000 hab \\
\hline & Total leitos hosp / 1000 hab \\
\hline & Taxa Mort Infantil \\
\hline & Índice de Educação \\
\hline & $\begin{array}{c}\text { População que vive em } \\
\text { domicílios com saneamento }\end{array}$ \\
\hline & Déficit Habitacional \\
\hline \multirow{3}{*}{ Econômico } & Nível de emprego \\
\hline & $\begin{array}{l}\text { Renda média população } \\
\text { (salário mínimo) }\end{array}$ \\
\hline & Vulnerabilidade à pobreza \\
\hline
\end{tabular}

Fonte: Elaborado pelos autores

Com as variáveis escolhidas dentro de cada dimensão, o estágio seguinte foi o de ajustar os dados das distintas variáveis e suas particulares ordens de grandeza, convertendo-as em indicadores por meio das etapas seguintes. Cabe salientar que neste trabalho foi utilizada metodologia análoga a Silva et al. (2017) e Fiore et al. (2017) em seus trabalhos, nos quais foram consideradas as sequentes etapas.

- Escolha das variáveis a ser utilizada; 
- Transformação dos indicadores em índices com valores entre 0 e 1 ;

- Seleção de valores de referência que denotem o pior e melhor valor possível para o indicador, a fim de estabelecer os limites teóricos de variação;

O melhor ou pior valor de cada variável, que foi transformada em indicador, decorreu apenas de seus valores absolutos dentro da realidade estadual, o melhor sendo o mais bem avaliado dentro do estado do Rio de Janeiro, e o pior de modo análogo.

- Consumação do cálculo do índice através da fórmula: Indicador $=($ Valor Encontrado - Pior Valor) / (Melhor Valor - Pior Valor)

Concluídas as etapas, somam-se os indicadores da respectiva dimensão e divide-se o resultado pelo número total de variáveis, alcançando-se assim a média, que corresponde ao índice de sustentabilidade do município.

\section{RESULTADOS E DISCUSSÃO.}

TABELA 1. Indicadores Ambientais propostos para o Município de Maricá

\begin{tabular}{|c|c|c|c|c|c|}
\hline Dimensão & Variável & $\begin{array}{l}\text { Valor } \\
\text { Maricá }\end{array}$ & $\begin{array}{l}\text { Pior } \\
\text { Valor }\end{array}$ & $\begin{array}{l}\text { Melhor } \\
\text { Valor }\end{array}$ & Indicador \\
\hline \multirow{7}{*}{ Ambiental } & $\begin{array}{l}\text { Abastecimento água potável área urbana } \\
\text { (domicílios) }\end{array}$ & 57,98 & 27,76 & 97,64 & 0,4325 \\
\hline & $\begin{array}{c}\text { Perda de água tratada (média anual } \\
\text { diária) }\end{array}$ & 22,3 & 67,52 & 19,04 & 0,9328 \\
\hline & Qualidade de água & 37,83 & 17,7 & 82,1 & 0,3126 \\
\hline & Média Per capita de resíduos (kg/ dia.hab) & 0,79 & 0,71 & 1,32 & 0,1311 \\
\hline & Arborização de vias públicas (\%) & 45,6 & 25,7 & 94,6 & 0,2888 \\
\hline & ICMS verde (IFCA) & 1,7825 & 0 & 4,39 & 0,4061 \\
\hline & $\begin{array}{l}\text { Área Desmatada }\left(\mathrm{km}^{2}\right) \\
\text { Indicadores Qualidade AR }\end{array}$ & \multicolumn{4}{|c|}{$\begin{array}{l}\text { Dados não encontrados } \\
\text { Dados não encontrados }\end{array}$} \\
\hline
\end{tabular}

Fonte: Elaborado pelos autores

A análise dos dados na dimensão ambiental, explicitada na Tabela 1 demonstrou uma expansão populacional pouco ordenada culminando em indicadores alarmantes. Principalmente no que tange a qualidade da água consumida pela população e a média de resíduos per capta. Os estudos de Oliveira Filho e Lima Neto (2017) reforçam que as consequências desses fatores somados a uma gestão ambiental preambular é capaz de acarretar impactos socioeconômicos e ambientais graves especialmente nas áreas mais carentes de infraestrutura básica

O resultado no índice de perda de água tratada do município de Maricá, muito próximo de um dos menores índices de perda de água tratada do estado do Rio de Janeiro foi dado pela economia e um bom gerenciamento dos recursos hídricos, fatores que, de acordo com o estudo de Carvalho et al. (2015) contribuíram para a redução do consumo de energia na produção de água potável. Porém, como aludido no mesmo estudo, ações de engenharia, gerenciamento e reuso da água, necessitam ser tomadas juntamente com o cuidado dos efluentes a fim de aliar a necessidade de crescimento à proteção do meio ambiente. Foi constatado também por Sobrinho e Borja (2016) que o índice de perda de água quando utilizado como 
uma ferramenta de monitoramento constante configura uma estratégia constante e eficiente nas políticas dos prestadores de serviço de abastecimento.

Com diversas funções sociais e ambientais, como de fornecer o bem-estar, lazer, recreação, isolamento acústico, micro clima, entre outros, as áreas verdes exercem papel positivo na qualidade de vida das pessoas. Como corrobora o estudo de da Silva et al. (2016), a incumbência de áreas verdes vai muito além de estética, o papel educativo e ecológico age como elemento mitigador das condições adversas da urbanização. O município de Maricá apresenta significativo índice de arborização de vias públicas, e contínua melhoria de seus parques e praças públicas, além de um índice final de conservação ambiental dentro da média estadual, porém a área verde municipal ainda indica premência de investimentos em estudos que visam não só o aumento da quantidade, mas também da compatibilidade de espécies em estruturas urbanas, como apontaram Rocha et al. (2004) em seu trabalho.

Os indicadores da dimensão ambiental, portanto, foram capazes de demonstrar e quantificar os efeitos negativos das ações antrópicas nessa dimensão. Os impactos no meio ambiente dessa magnitude colocam em perigo a saúde e atividades econômicas como o turismo. Segundo estudos de Sanches e Schmidt (2016) a atividade do turismo possui alto potencial de proporcionar transformações expressivas na qualidade de vida da população, com isso, a má conservação do meio mina um segmento capaz de contribuir para o desenvolvimento em cadeia de uma localidade.

$\mathrm{Na}$ exploração dos dados da dimensão social (Tabela 2) observa-se que a área da saúde apresenta uma cobertura assistencial pública para a população do município insuficiente. Como Bezerra et al. (2017) observaram em seu estudo os fatores socioeconômicos estão intrinsecamente ligados aos riscos de doenças e a taxa de mortalidade. O grande deslocamento em busca de assistência média, que denotam uma inadequação às áreas de abrangência na saúde, podem agravar quadros, levando ao óbito. Constatou- se por fim, que uma melhora na saúde auxilia no desenvolvimento da população de modo geral.

TABELA 2. Indicadores sociais propostos para o município de Maricá

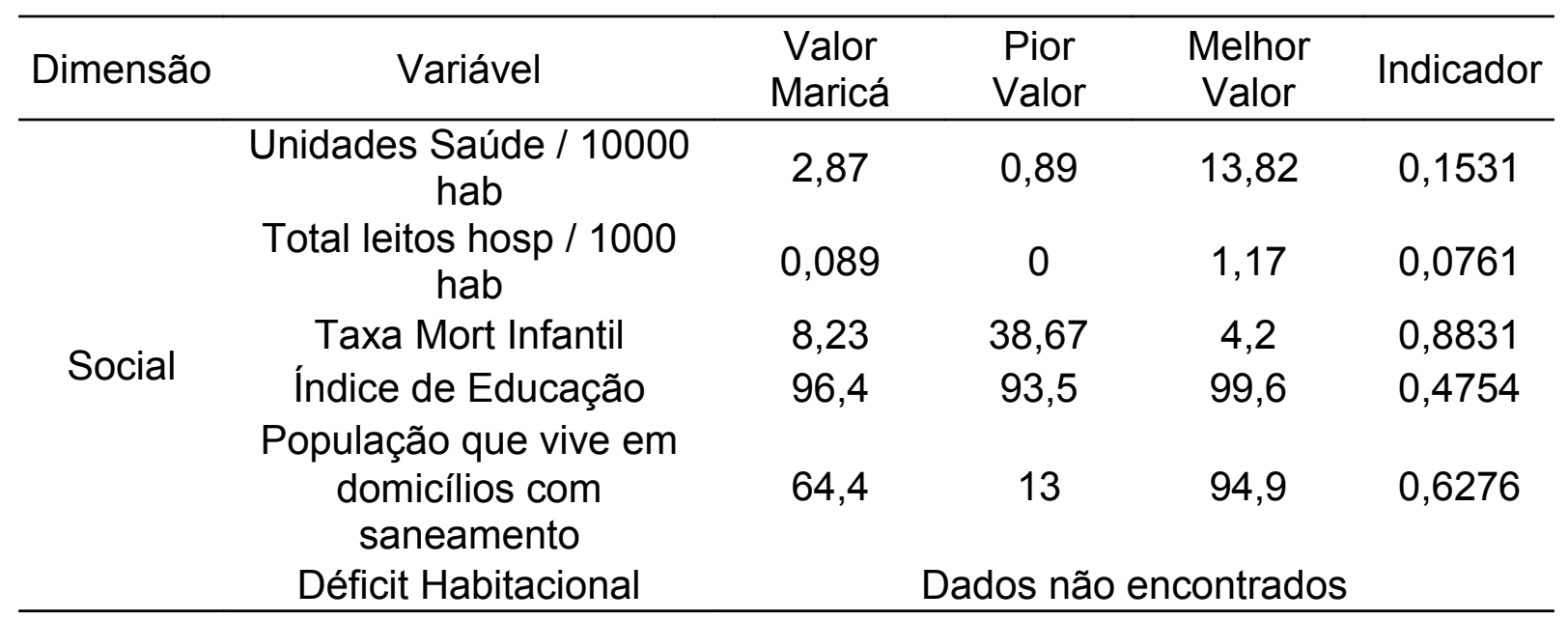

Fonte: Elaborado pelos autores

Questões de saúde pública e degradação do meio ambiente estão demasiadamente correlacionadas com a deficiência dos serviços de saneamento 
básico. Os estudos de Garcia e Ferreira (2017) apontaram que a falta ou debilidade nos serviços de saneamento básico favoreceu o aumento de infecções de origem presumível, além de ter sido a principal causa de destruição das bacias hidrográficas localizadas nas grandes metrópoles. A carência nessa vertente da dimensão social permite a disseminação de doenças por via hídrica e impacta negativamente a economia, biodiversidade e educação segundo os autores.

A débil capacidade de leitos em unidades de saúde, aquém da demanda, provoca atrasos nos diagnósticos e filas por atendimento, situação mais comum em localidades com maior vulnerabilidade social e econômica. Sendo os hospitais um dos recursos de saúde mais onerosos à sociedade, Nascimento (2015) aponta que, o gerenciamento de leitos hospitalares é então uma ferramenta crucial na distribuição de leitos de forma equitativa a fim de atender o maior número de necessitados.

O índice de educação do município de Maricá está intrinsecamente ligado ao índice econômico, e apresenta baixo desempenho devido à falta de uniformidade social dos municípios localizados no seu entorno, fator este que acentua a disparidade educacional, como verificado também por Santana et al. (2018) em seu trabalho. Ainda congruente ao estudo citado, a logística e composição da oferta de vagas escolares, responsabilidade dos municípios, fez com que as políticas públicas educacionais municipais desempenhassem papel fundamental para que a isonomia social fosse efetuada (SANTANA et al.,2018).

A análise econômica dos dados observados na Tabela 3 reflete o que é constatado intuitivamente pela população do município de Maricá. Em um município de promessas de dinamismo econômico e potencial turístico, dada à diversidade natural, o percentual populacional com emprego formal ainda é discreto, conduzindo a um nível salarial populacional pequeno, dentro da realidade do estado do Rio de Janeiro.

TABELA 3. Indicadores econômicos propostos para o município de Maricá.

\begin{tabular}{lccccc}
\hline \multirow{2}{*}{ Dimensão } & Variável & $\begin{array}{c}\text { Valor } \\
\text { Maricá }\end{array}$ & $\begin{array}{c}\text { Pior } \\
\text { Valor }\end{array}$ & $\begin{array}{c}\text { Melhor } \\
\text { Valor }\end{array}$ & Indicador \\
& Nível de emprego & 13,7 & 8,5 & 62,7 & 0,0959 \\
Econômica & $\begin{array}{c}\text { Renda média população } \\
\text { (salário mínimo) } \\
\text { Vulnerabilidade à } \\
\text { pobreza }\end{array}$ & 2,1 & 1,6 & 7,5 & 0,0847 \\
& 38,72 & 81,6 & 7,72 & 0,5804 \\
\hline
\end{tabular}

Fonte: Elaborado pelos autores

O baixo índice de emprego formal culminou em uma alta vulnerabilidade a pobreza. Assim como defenderam Santos et al. (2017) em seu trabalho a rotatividade de empregos e volatilidade da renda acabam por afetar os níveis de bem estar presentes e futuros da população.

O nível de renda relacionou-se também à degradação ambiental, como demonstrou Oliveira (2017) em seu estudo, atestando que a condição de pobreza da população influenciou seu nível de exposição à ambientes degradados. O grau de destruição deste ambiente gerou uma perda na capacidade produtiva do solo e ENCICLOPÉDIA BIOSFERA, Centro Científico Conhecer - Goiânia, v.15 n.27; p. 188 2018 
influenciou diretamente o desenvolvimento econômico e social, impactando as outras dimensões avaliadas.

$\mathrm{Na}$ Tabela 4 podem ser observados os índices correspondentes a todas as dimensões. A dimensão social encontra-se com peso maior (peso 2) que as demais, pois segundo os estudos de Silva et al. (2017) a esfera social, embora uma das mais negligenciadas determina como a população faz as suas escolhas, e isto impacta toda uma localidade. Os autores constataram analogamente em seu estudo que ao envolver a comunidade no que é proposto, são introduzidas ao sistema forças significativas que tornam possível o engajamento da população em prol de objetivos que impactam positivamente o local.

TABELA 4. Índices por dimensão e total de sustentabilidade municipal.

\begin{tabular}{cccc}
\hline Dimensão & Índice & Peso & Total \\
\hline Ambiental & 0,4173 & 1 & \\
Social & 0,4431 & 2 & 0,3893 \\
Econômica & 0,2537 & 1 & \\
\hline
\end{tabular}

Fonte: Elaborado pelos autores

Fica evidenciado portanto, na coluna Total (Tabela 4) o quão sustentável é o município dentro da realidade estadual, sendo 0,3893 o índice de sustentabilidade atual segundo as variáveis propostas neste estudo. Valor este considerado baixo ao comparar-se com o cenário ideal $(1,00)$. Observa-se assim que município ainda necessita percorrer um longo trajeto no aprimoramento de características que atendam a população nas três dimensões da sustentabilidade. Ressalta-se que se medidas forem tomadas nas áreas mais negligenciadas apontadas pelos indicadores propostos, mais rápida será a evolução dessa realidade.

\section{CONCLUSÃO}

Embora esforços estejam em curso por parte da administração pública, alguns pontos necessitam de atenção especial. Há pontos positivos detectados pela pesquisa na dimensão social, podendo ser citado como tal à baixa taxa de mortalidade infantil, o que demonstra um compromisso público na assistência materno-infantil no município. E na dimensão ambiental, como a média anual diária de perda de água tratada, que evidencia uma preocupação por parte da administração pública em relação ao manejo correto desse recurso natural. Porém a dimensão econômica carece de investimentos.

É crucial que haja uma atenção especial aos problemas ambientais decorrentes do nível de renda da população do município, para que mecanismos de enfrentamento concomitantes às duas questões sejam criados. A adoção de atitudes que reduzam os impactos de causa-efeito e melhorias de infraestrutura, saúde, conservação de áreas de preservação permanente pode contribuir para um maior nível de desenvolvimento sustentável na região.

Os indicadores propostos no presente estudo podem ser utilizados pela administração pública como ferramenta de avaliação, auxiliando na tomada de decisões, a fim da construção de uma sociedade mais responsável e eficiente no uso dos seus recursos. Por sua vez, a análise da evolução das variáveis estudadas 
também pode indicar quão satisfatória ou frustrada é a administração pública no cumprimento do seu papel.

\section{REFERÊNCIAS}

BEZERRA, A. B.; FREIRE, K. M. R.; GURGEL, H. da C.; RAMALHO, W. M. Dinâmica espacial de nascidos vivos e óbitos infantis nas regiões de saúde do distrito federal em 2012. Revista Brasileira de Geografia Médica e da Saúde, v. 13 , n. 26, p. 126-138, 2017. Disponível em: <http: //dx.doi.org/10.14393/Hygeia132610>. Doi: 10.14393/Hygeia132610.

BORGES, M. L.; EDUARDO, R.; ORDOÑEZ, C. O uso dos relatórios de sustentabilidade como fonte de pesquisas acadêmicas $\square$ tendências e gaps a serem explorados. Revista Metropolitana de Sustentabilidade. v. 8, 2018.

BRAGA, T. M.; FREITAS, A. P. G. De; DUARTE, G. D. S.; SOUSA, J. C. Índices de Sustentabilidade Municipal: o Desafio de Mensurar. Revista Nova Economia, v. 14, n. 3, p. 11-33, 2004. Disponível em: <http://www.face.ufmg.br/novaeconomia/sumarios/v14n3/140301.pdf>.

BRITO, B. N. de; SANTOS, G. M. dos; CAMPOS, A. C. Identificação De Processos De Degradação Ambiental Urbana Utilizando Sistemas De Informções Geográficas $\square$ : Microbacia Do Córrego Caveiras , Goiânia - Goiás . IBEAS- Instituto Brasileiro de Estudos Ambientais, p. 1-9, 2013.

CARVALHO, W. S.; FERNANDES, P. S. R.; DOURADO, J. D. A.; MAGALHÃES, C. R.; BERNARDES, B. O. Consumo e perda de água potável na região metropolitana do rio de janeiro. Revista Produção e Desenvolvimento, v. 1, n. 3, p. 80-89, 2015.

DA SILVA, A. D. P.; DOS SANTOS, A. F.; DE OLIVEIRA, L. M. Índices de área verde e cobertura vegetal das praças públicas da cidade de Gurupi, TO. Floresta, v. 46, n. 3, p. 353-361, 2016. Disponível em: < http: //dx.doi.org/10.5380/rf.v46i3.40052 > Doi: $10.5380 /$ rf.v46i3.40052.

DATASUS. Cadastro Nacional de Estabelecimentos de Saúde. Disponível em: <http://cnes.datasus.gov.br/>. Acesso em: 13 jan. 2018.

DE OLIVEIRA, G. B.; LIMA, J. E. de S. Elementos endógenos do desenvolvimento regional: considerações sobre o papel da sociedade local no processo de desenvolvimento sustentável. Revista da FAE, Curitiba, v. 6, n. 2/3, p. 29-37, 2003. Disponível em: <http://www.fae.edu/publicacoes/pdf/revista_da_fae/fae_v6_n2/03_Gilson.pdf>.

FIORE, E. G.; BANDEIRANTES, A.; ALEGRE, M.; MACIEL, V. F. Proposal of quality of life indicator for são paulo city.Revista de Economia Mackenzie, v. 5, n. 3, p. 102-129, 2007. Disponível em: < http://132.248.9.34/hevila/RevistadeeconomiaMackenzie/2007/vol5/no5/4.pdf >.

GARCIA, M. S. D.; FERREIRA, M. de P. Saneamento básico $\square$ meio ambiente e dignidade humana. Basic sanitation $\square$ environment and human dignity. Periodicos PUC Rio - Dignidade Re-Vista, v. 2, n. 1, p. 12, 2017. 
IBGE. IBGE | Brasil em Síntese | Rio de Janeiro | Maricá | Panorama. Disponível em: <https://cidades.ibge.gov.br/brasil/rj/marica/panorama>. Acesso em: 28 jan. 2018.

INCID. O Direito a água, Estudos Instituto Brasileiro de Análises Sociais e Econômicas-IBASE, Governo Federal- Brasil, 2016.

KOTSUBO, B. F. de S. K.; FRACACIO, G.; CASSIANO, D. P. T. A. M.; MOSCHINI, L. E.; CATOJO, A. M. Z. Avaliação da qualidade dos corpos hídricos frente ás ações antrópicas no município de Santa Lúcia - SP. Revista brasileira de geografia, v. 10, n. 1, p. 317-331, 2017. Disponível em: <http://biblat.unam.mx/pt/revista/revistabrasileira-de-geografia/articulo/fronteira-e-urbanizacao-repensadas>.

MORAIS, P. S. de A.; LIMA, J. H. de M.; ABREU, B. S.; ABREU, I. G.; ABREU, P. S. Educação ambiental como estratégia na atenção primária em saúde. Polêmica! CA Revista Eletrônica, v. 13, n. 3, 2014.

NASCIMENTO, A. B. do. Gerenciamento de leitos hospitalares: análise conjunta do tempo de internação com indicadores demográficos e epidemiológicos. Revista de Enfermagem e Atenção à Saúde, v. 4, n. 1, p. 65-78, 2015.

OLIVEIRA, D. B. O. A inter-relação entre pobreza e meio ambiente para os municipios de Minas Gerais. Revista de Economia e Agronegócio, v. 15, n. 1, p. 84, 2017.

OLIVEIRA, G.; SCAZUFCA, P.; MARCATO, F. S.; ORJUELA, G.; AROUCA, L. F. A. F.; AGUIAR, S. S. Perdas de Água: Desafios ao Avanço do Saneamento Básico e à Escassez Hídrica. Estudos Instituto Trata Brasil p. 112, 2015. Disponível em: $<$ http://tratabrasil.org.br/datafiles/estudos/perdas-de-agua/Relatorio-Perdas2015.pdf>.

OLIVEIRA FILHO, A. A. de; LIMA NETO, I. E. Modelagem da qualidade da água do rio Poti em Teresina (PI). Engenharia Sanitaria e Ambiental, v.1 ,n.1, p.1-12, 2017. Disponívem em: < http: //dx.doi.org/10.1590/s1413-41522017142354 > Doi: 10.1590/s1413-41522017142354.

REDE INTERAGENCIAL DE INFORMAÇÃO PARA A SAÚDE. Indicadores básicos para a saúde no Brasil: conceitos e aplicações. Organização Pan-Americana da Saúde, p. 349, 2008. Disponível em: <http://bases.bireme.br/cgibin/wxislind.exe/iah/online/?

IsisScript=iah/iah. $x$ is \&src=google\&base=REPIDISCA\&lang=p\&nextAction=Ink\&exprS earch=7469\&indexSearch=ID>. 